\title{
Prevalence and determinants of anaemia among children aged 0-59 months in a rural region of Armenia: a case-control study
}

\author{
Anahit Demirchyan ${ }^{1, *}$, Varduhi Petrosyan ${ }^{1}$, Viktoria Sargsyan ${ }^{2}$ and Kim Hekimian ${ }^{3}$ \\ ${ }^{1}$ School of Public Health, American University of Armenia, 40 Marshal Baghramian Avenue, Yerevan 0019, \\ Armenia: ${ }^{2}$ Health Learning Hub, World Vision International Middle East and Eastern Europe Regional Office, \\ Yerevan, Armenia: ${ }^{3}$ Institute of Human Nutrition, Columbia University, New York, NY, USA
}

Submitted 26 March 2015: Final revision received 8 July 2015: Accepted 14 July 2015: First published online 2 September 2015

\begin{abstract}
Objective: Despite the trend of increasing prevalence of childhood anaemia in Armenia, no studies exploring its risk factors have been conducted in the country. The present study aimed to investigate the prevalence and determinants of childhood anaemia in rural Armenia.

Design: Blood Hb level was measured among a representative sample of children using the HemoCue Hb201 + analyser. The revealed cases with anaemia were compared with randomly selected non-anaemic controls. Mothers of cases and controls were interviewed. Logistic and linear regression models were fitted to identify the risk factors of anaemia and low $\mathrm{Hb}$ level, respectively.

Setting: Talin communities, Aragatsotn Province, Armenia.

Subjects: Children under 5 years of age in Talin region.

Results: Of the 729 studied children, 32.4\% were anaemic with $14.7 \%$ having moderate/severe anaemia. Infants were the most affected group with $51 \cdot 1 \%$ being anaemic before 6 months and $67.9 \%$ at 6-12 months of age. Fitted regression models identified the following predictors of anaemia: younger age, male gender, shorter birth length, anaemia during pregnancy, lower meal frequency per day, lack of meat in the diet, using dung cakes for heating and living in a community that received an incomplete set of nutrition interventions.

Conclusions: The study identified several modifiable risk factors that could be targeted to reduce childhood anaemia in rural Armenia and, possibly, in rural areas in other low-/middle-income countries. The suggested interventions include prevention and treatment of anaemia during pregnancy, provision of adequate complementary feeding to children with inclusion of meat in their daily diet and reduction of their exposure to biomass fuel smoke.
\end{abstract}

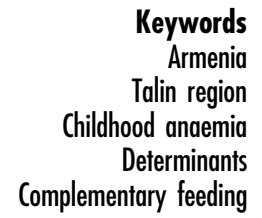

Anaemia is one of the most common public health problems worldwide. About one-third (32.9\%) of the world's population was anaemic in 2010 and anaemia was responsible for 68.3 million years lived with disability ${ }^{(1)}$. Although a steady decrease in the prevalence of anaemia was observed worldwide since the mid-1990s, the rates of anaemia among women and children younger than 5 years old have changed only slightly ${ }^{(2)}$. Children aged 0-59 months carry the highest burden of anaemia ( $43 \%$ in $2011)^{(1,2)}$. Anaemia has detrimental and possibly irreversible consequences on a young child's development as it delays brain maturation, leading to impaired motor development and diminished cognitive functioning ${ }^{(3-5)}$. Anaemia is associated with a child's retarded linear growth ${ }^{(6-8)}$, reduced physical activity ${ }^{(5)}$ and impaired cell-mediated immunity leading to higher susceptibility to infections ${ }^{(5,9-11)}$.
Although there are various underlying causes of anaemia, Fe deficiency is the top cause globally ${ }^{(1)}$. According to recent estimates, the proportion of all childhood anaemia resulting from $\mathrm{Fe}$ deficiency ranges from $63 \%$ in Europe to $34 \%$ in Africa, while the proportion of severe anaemia attributable to Fe deficiency is over $50 \%$ globally $^{(2,3)}$. Low consumption of meat products is considered to be the major cause of Fe deficiency in young children, especially at weaning age when the Fe requirement is high due to rapid growth and $\mathrm{Fe}$ intake from inadequate complementary feeding is low ${ }^{(4,12)}$. Thus, younger age and insufficient consumption of bioavailable $\mathrm{Fe}$ are among well-established determinants of childhood anaemia $^{(6,8,12-15)}$. Other factors commonly related to anaemia in children include male gender, family's poor socioeconomic status (SES), maternal anaemia (especially 
during pregnancy) and child's stunted growth ${ }^{(6-8,12,14-17)}$. In some populations, a substantial proportion of anaemia is attributable to sickle cell disorder, thalassaemia, hookworm, schistosomiasis and malaria ${ }^{(1)}$. In some areas, environmental contamination with heavy metals is an increasing concern, inducing anaemia among other health adversities $^{(18)}$.

In Armenia, the Demographic and Health Surveys (ADHS) 2000 and 2005 are the only sources that provided population-based data on anaemia prevalence among 6-59month-old children in the country. ADHS 2005 identified $36.5 \%$ prevalence of anaemia among children under 5 years of age (under- 5 s) countrywide (using the HemoCue technique, altitude-adjusted $\mathrm{Hb}$ levels and $110 \mathrm{~g} / \mathrm{l}$ cut-off value ${ }^{(19)}$. This rate exceeded the ADHS 2000 rate $(23.9 \%)^{(20)}$ over 1.5 times, suggesting the possibility of a growing public health problem with childhood anaemia in Armenia. According to the WHO classification, Armenia is in the group of countries having a problem of anaemia of moderate public health significance (a prevalence ranging from 20.0 to $39.9 \%)^{(21)}$. Nevertheless, to our knowledge, no studies exploring risk factors of anaemia among children have been conducted in the country.

The present study was conducted in Talin - a rural region of Armenia which is located on the south-western slope of Mount Aragats, 1200-3300 m above sea level, and is one of the four regions of Aragatsotn Province. It includes one urban and forty rural communities with a total population of 31600 , urban/rural population ratio of 1:5, and children under 18 years of age constitute one-third of the population. Agriculture plays the leading role in the region's economy. However, the efficiency of agriculture is hampered because of insufficient irrigation systems, unfavourable climate conditions and lack of agricultural machinery. Selling agricultural products is also a major challenge in the region due to poor condition of roads and transportation. According to a 2011 census $^{(22)}$, about $10 \%$ of the population in Aragatsotn Province is employed and $27 \%$ is self-employed in farming, while over $50 \%$ is dependant or retired. The prevalence of anaemia among 6-59-month-old children in the province, according to ADHS, was stable $-25.5 \%$ in 2000 and $26.5 \%$ in 2005. However, the rate of severe anaemia (Hb below $70 \mathrm{~g} / \mathrm{l}$ ) among them increased from $1.4 \%$ in 2000 to $7 \cdot 1 \%$ in $2005^{(19,20)}$.

Since 2008, World Vision (WV) Armenia has targeted the majority of communities in Talin region with activities in the sectors of economic development, HIV/AIDS prevention, education and nutrition. The activities were carried out through community involvement and local capacity building. Interventions to improve the nutritional status of women and children aimed to promote healthy nutrition in general and included seminars for women on child care and nutrition, dissemination of education materials on these topics, establishing Mother Support Groups, promoting locally available healthy foods and capacity building of primary health-care providers. Some of the targeted communities received the full set of five interventions listed above, while others received a partial set of two to four interventions. Neither the prevalence of anaemia nor its risk factors were ever studied in the region and no specific anaemia-reduction interventions were carried out. The aim of the present study was to measure the prevalence of anaemia among under- 5 s residing in these communities and identify the determinants of anaemia. The results of the study could help WV and other stakeholders to expand their health promotion activities to include anaemia reduction.

\section{Methods}

\section{Study design and participants}

The study participants were children aged 0-59 months residing in WV target communities of Talin region, Aragatsotn Province. A cross-sectional study design was applied to identify the prevalence of anaemia among them. The study utilized a probability-proportional-to-size (under- $5 \mathrm{~s}$ population size) cluster sampling design to select communities via systematic random sampling. Then study participants were randomly selected from enumerated ambulatory lists of under- $5 \mathrm{~s}$ in the selected communities. The study used the statistical software package STATA version 10 for sample size calculation, applying the formula for one-sample comparison of proportion (taken as $\left.0.265^{(19)}\right)$ to a hypothesized value $(0.215)$ to detect a difference of $5 \%$ with 0.8 power and type 1 error of 0.05 . An estimated cluster design effect coefficient of 1.25 was applied to the calculated sample size of 587 , increasing it to 734 , which was further increased to 800 anticipating $\sim 10 \%$ non-response. The total number of under- $5 \mathrm{~s}$ in the targeted communities was 2080, meaning that the crosssectional study was designed to include over one-third of the eligible population. Selected children were invited to local ambulatories and underwent $\mathrm{Hb}$ measurement in capillary blood taken from a finger. The study used the HemoCue $\mathrm{Hb} 201+$ analyser to measure blood $\mathrm{Hb}$ concentrations, because it provides quickness of measurement, ease of use and maintenance combined with proven precision and accuracy ${ }^{(23)}$. The HemoCue system is based on the cyanmethaemoglobin method - the reference laboratory method for $\mathrm{Hb}$ measurement used for standardization of other methods and is generally recommended for use in population surveys as a stable and reliable method in field settings ${ }^{(21)}$. Trained field teams, each comprised of a paediatrician and a laboratory nurse, conducted the measurements. As the majority of communities in Talin region are more than $1000 \mathrm{~m}$ above sea level, $\mathrm{Hb}$ concentrations obtained through HemoCue were further adjusted for the area's altitude applying the adjustment values recommended by the $\mathrm{WHO}^{(21)}$. Cut-off values to diagnose anaemia in children aged under 5 years 
were altitude-adjusted $\mathrm{Hb}$ level $<70 \mathrm{~g} / \mathrm{l}$ for severe, 70-99 g/1 for moderate and 100-109 g/l for mild anaemia $^{(21)}$. In addition, the field teams conducted weight and height measurements of each child, reviewed his/her ambulatory chart and abstracted data on the child's age, gender, weight and length at birth, term of birth and any chronic conditions diagnosed.

After the cross-sectional study, the research team conducted a case-control study to identify determinants of anaemia among children aged 0-59 months in Talin region. The decision to conduct a case-control study was based on both feasibility and efficiency considerations, as the study was limited in time and resources to conduct interviews with mothers of all children included in the cross-sectional study sample. A case/control rate of 1:1 was applied. All children identified as having Hb level less than $105 \mathrm{~g} / \mathrm{l}$ were included in the case-control study as cases. The study team randomly selected controls from the pool of studied children identified as having $\mathrm{Hb}$ level of $110 \mathrm{~g} / \mathrm{l}$ or more, using the Select Random Sample of Cases function from the SPSS menu. The research team purposefully avoided age and gender matching of cases and controls, as matched characteristics cannot be investigated further, while one of the aims of the study was to identify whether age and/or gender were independent determinants of anaemia, so that target groups for anaemiareduction interventions could be correctly defined by age and gender. Hb cut-off values of less than $105 \mathrm{~g} / 1$ to select cases and $110 \mathrm{~g} / \mathrm{l}$ or more to select controls were applied with the intention to have definite cases with anaemia and controls with no anaemia to minimize misclassification bias in the case-control study sample. A number of studies have recommended and used $\mathrm{Hb}$ values of $105 \mathrm{~g} / \mathrm{l}$ or less as more accurate cut-offs to diagnose anaemia in infants and young children ${ }^{(16,24-29)}$. Trained interviewers, blind to the anaemia status of children, conducted face-to-face interviews with mothers of cases and controls, using a structured questionnaire. Data collection for the prevalence study took place in October-November 2013 and for the case-control study in December 2013.

\section{Variables}

The dependent variable of the case-control study was the presence of anaemia in a child aged 0-59 months. Independent variables included potential risk or confounding factors of childhood anaemia ${ }^{(30)}$ and were grouped into the following subgroups: child's characteristics, maternal/birthrelated characteristics, child's nutrition patterns and living standards/environment. Child's characteristics included age, gender, birth length and weight, any diagnosis with intestinal worms during the last year, any significant blood loss in recent months and any recent lengthy diarrhoea. Maternal/ birth-related characteristics included mother's age (at the child's delivery), height, education, employment, anaemia during pregnancy, rhesus conflict between the mother and child, child's birth order, delivery term, delivery mode, inter-birth interval before the child's birth and mother's child-care knowledge score. Child's nutrition patterns included breast-feeding initiation time (within the first hour after birth or later), duration of exclusive and any breastfeeding, age at introduction of tea, juice and cow's milk, food diversity score, number of meals per day and consumption of cow's milk and meat in the last $24 \mathrm{~h}$. Living standards and environment included child's family size, SES coefficient, household heating mode (heating with dung cakes $v$. hot water, electric, gas/oil or coal/wood heating), number of times the child's hands were washed per day, use of soap during hand-washing and whether the complete set of WV interventions was carried out in the community.

Most independent variables were measured based on single items, with exception of the three summative scores developed by the authors: child's food diversity score, mother's child-care knowledge score and family's SES coefficient. Child's food diversity score (with a range of 0-13) was a cumulative number of the food types (of thirteen adapted from the food category list used in ADHS questionnaire ${ }^{(31)}$ ) the child consumed during the last $24 \mathrm{~h}$, as reported by the mother. Mother's child-care knowledge score (with a range of 0-10) was a sum of correct replies to ten questions on different aspects of child care. For family's SES coefficient, the study used SES regression coefficients for the first factor (explaining $40 \%$ of the variance in the sample) from the principal component analysis with the items on family's average monthly expenditures, perceived living standards and possession of various convenience/luxury items. The online supplementary material presents the items used to construct the scores and the SES coefficient.

\section{Analysis}

The research team used the cross-sectional study sample to identify the prevalence of anaemia. The characteristics of those with and without anaemia in the case-control study sample were analysed descriptively and compared statistically using Student's $t$ test (for normally distributed variables) or the Mann-Whitney $U$ test (for non-normally distributed variables) for means and the $\chi^{2}$ test for proportions. This was followed with univariate and multivariate logistic regression analyses with the outcome of anaemia status. The research team dichotomized all the nominal/ordinal variables before entering them into logistic regression analyses to enhance the interpretability of the findings. The continuous variables were treated as continuous after checking their linearity on the logistic scale with the outcome of anaemia status ${ }^{(32)}$. The multivariate analyses included all the variables associated with the outcome at the $P<0.25$ level in the univariate analysis, as recommended by Hosmer and Lemeshow ${ }^{(32)}$. During fitting the models, the research team entered independent variables into multivariate analysis in different combinations using the enter function. The fit of the final logistic 
Table 1 Prevalence of anaemia ( $\mathrm{Hb}$ below $110 \mathrm{~g} / \mathrm{l}$ ) among children aged 0-59 months in Talin region, Aragatsotn Province, Armenia, 2013

\begin{tabular}{|c|c|c|c|c|c|c|c|}
\hline \multirow[b]{3}{*}{ Age (months) } & \multirow[b]{3}{*}{ Sample $N$} & \multicolumn{6}{|c|}{ Prevalence of anaemia } \\
\hline & & \multicolumn{2}{|c|}{ Any $(\mathrm{Hb}<110 \mathrm{~g} / \mathrm{l})$} & \multicolumn{2}{|c|}{ Moderate $(\mathrm{Hb}=70-99 \mathrm{~g} / \mathrm{l})$} & \multicolumn{2}{|c|}{ Severe $(\mathrm{Hb}<70 \mathrm{~g} / \mathrm{l})$} \\
\hline & & $\%$ & $n$ & $\%$ & $n$ & $\%$ & $n$ \\
\hline$<6.0$ & 47 & $51 \cdot 1$ & 24 & $17 \cdot 0$ & 8 & & \\
\hline $6.0-11.9$ & 84 & 67.9 & 57 & 40.5 & 32 & $2 \cdot 4$ & 2 \\
\hline $12 \cdot 0-17.9$ & 76 & $52 \cdot 6$ & 40 & $32 \cdot 8$ & 22 & 3.9 & 3 \\
\hline $18.0-23.9$ & 63 & 38.1 & 24 & 25.4 & 15 & 1.6 & 1 \\
\hline $24.0-29.9$ & 86 & 31.4 & 27 & 11.6 & 10 & & \\
\hline $30.0-35.9$ & 77 & $27 \cdot 3$ & 21 & 5.2 & 17 & & \\
\hline $36.0-41.9$ & 88 & 12.5 & 11 & $2 \cdot \overline{3}$ & 2 & & \\
\hline $42.0-47.9$ & 82 & 20.7 & 17 & $6 \cdot 1$ & 5 & & \\
\hline $48.0-53.9$ & 65 & $12 \cdot 3$ & 8 & $3 \cdot 1$ & 2 & & \\
\hline $54.0-59.9$ & 61 & 11.5 & 7 & 1.6 & 1 & & \\
\hline Total & 729 & 32.4 & 236 & 13.9 & 101 & 0.8 & 6 \\
\hline
\end{tabular}

$N$, number of children in each age group; $\mathrm{Hb}$, altitude-adjusted $\mathrm{Hb}$ level.

regression model was tested via pseudo $R^{2}$, the HosmerLemeshow goodness-of-fit test and the area under the receiver-operating characteristic curve. The research team fitted also a multiple linear regression model with the outcome of $\mathrm{Hb}$ concentration in capillary blood to take advantage of using the whole variability of the continuous outcome variable. All the variables included in the final logistic or linear regression models were checked for interaction. Collinearity issues between these variables were also checked by applying variance inflation factor statistics. The analyses were conducted using the STATA version 10 and SPSS version 11 statistical software packages.

\section{Results}

Overall, 729 children younger than 5 years (mean age 30.5 (SD 16.3) months) underwent $\mathrm{Hb}$ measurement. Of them, 404 (55.4\%) were boys and 325 (44.6\%) girls. The altitudeadjusted mean $\mathrm{Hb}$ level among the studied children was 114.3 (SD 14.1) g/l (range 60-152 g/l). The prevalence of anaemia in this sample, defined as altitude-adjusted blood Hb level below $110 \mathrm{~g} / \mathrm{l}$, was 32.4 (95\% CI 29.0, 35.9) \%. Of those identified as anaemic, $17.7 \%$ had mild anaemia, $13.9 \%$ had moderate and $0.8 \%$ had severe anaemia. The highest prevalence of anaemia (67.9\%) was detected among 6-12-month-old children, with the next highest rates in the age groups of 12-18 months (52.6\%) and 0-6 months $(51.1 \%)$. After 18 months of age, a clear decreasing tendency in the prevalence of anaemia was observed (Table 1). The proportion of moderate/severe anaemia was the highest among children aged 6-12 months.

The case-control study sample included 101 cases of anaemia with altitude-adjusted Hb level of less than $105 \mathrm{~g} / \mathrm{l}$ and eighty-seven healthy controls* with $\mathrm{Hb}$ concentration

*Although the case/control rate was initially taken as 1:1, after adjusting for altitude, $\mathrm{Hb}$ levels of only eighty-seven children involved as controls were $110 \mathrm{~g} / \mathrm{l}$ or more (with the rest having $\mathrm{Hb}$ levels in the range of $105-109 \mathrm{~g} / \mathrm{l})$ of $110 \mathrm{~g} / \mathrm{l}$ or more in capillary blood. There were no refusals for the interviews. Table 2 depicts the distribution of independent variables among anaemic children and controls and the results of statistical comparisons between them. Children with anaemia were significantly younger and had lower birth weight and shorter birth length (all $P<0 \cdot 001$ ). Mothers of cases and controls were not significantly different in their age at the child's delivery (25.4 and 24.9 years old, respectively), education (39.6\% and $36 \cdot 8 \%$ with graduate/higher education, respectively) or employment $(17.8 \%$ and $10.5 \%$, respectively). The proportion of preterm deliveries $(P=0.036)$ and caesarean sections $(P=0.037)$ with the given child was significantly higher among mothers of anaemic children compared with mothers of controls. The majority of nutrition-specific variables were significantly positively associated with child's anaemia status during univariate comparisons, including late initiation (after the first hour of life; $P=0.063$ ) and shorter duration of breast-feeding $(P=0.002)$, earlier introduction of cow's milk $(P=0.025)$ and juice $(P=0.040)$ into the child's diet, higher child's meal frequency per day $(P=0.015)$ and lower food diversity score $(P<0.001)$, and presence of cow's milk $(P=0.034)$ and absence of any meat $(P=0.005)$ in the child's diet in the last $24 \mathrm{~h}$. No difference was detected between the groups in the number of family members ( 6.5 for cases and 6.3 for controls) or child's birth order (1.9 for both). Of the variables on living standards and environment, use of dung cakes for heating the living quarters was positively associated with child's anaemia $(P=0.026)$, and living in communities where the complete set of WV interventions was carried out was inversely related to anaemia $(P<0 \cdot 001)$.

The final logistic regression model identified seven independent determinants of anaemia among 0-59-monthold children: child's age, gender, length at birth, maternal anaemia during pregnancy, child's meal frequency per day, burning dung cakes for heating and whether the complete set of WV interventions was carried out in the child's community (Table 3). After controlling for the remaining 
Table 2 Distribution of selected characteristics ${ }^{\star}$ between children aged 0-59 months with anaemia and controls in Talin region, Aragatsotn Province, Armenia, 2013

\begin{tabular}{|c|c|c|c|c|c|c|}
\hline \multirow[b]{2}{*}{ Characteristic } & \multirow[b]{2}{*}{$N$} & \multicolumn{2}{|c|}{$\begin{array}{c}\text { Anaemia, } \mathrm{Hb} \\
<105 \mathrm{~g} / \mathrm{l}(\text { ( } 101)\end{array}$} & \multicolumn{2}{|c|}{$\begin{array}{l}\text { No anaemia, } \mathrm{Hb} \\
>109 \mathrm{~g} / \mathrm{l}(\mathrm{n} 87)\end{array}$} & \multirow[b]{2}{*}{$P$ value } \\
\hline & & Mean or \% & SD or $n$ & Mean or \% & SD or $n$ & \\
\hline \multicolumn{7}{|l|}{ Child's characteristics } \\
\hline Age (months), mean and SD & 188 & $17 \cdot 0$ & $11 \cdot 1$ & $36 \cdot 3$ & 14.9 & $<0.001$ \\
\hline Birth weight $(\mathrm{kg})$, mean and SD & 188 & 3.0 & 0.6 & 3.3 & 0.5 & $<0.001$ \\
\hline Birth length $(\mathrm{cm})$, mean and SD & 188 & $50 \cdot 1$ & $3 \cdot 4$ & $51 \cdot 6$ & $2 \cdot 4$ & $<0.001$ \\
\hline \multicolumn{7}{|l|}{ Gender, $\%$ and $n$} \\
\hline Male & 109 & $58 \cdot 7$ & 64 & 41.3 & 45 & 0.103 \\
\hline Female & 78 & $46 \cdot 2$ & 36 & 53.8 & 42 & \\
\hline \multicolumn{7}{|l|}{ Diagnosed with intestinal worms in last year, $\%$ and $n$} \\
\hline Yes & 17 & $29 \cdot 4$ & 5 & $70 \cdot 6$ & 12 & 0.074 \\
\hline No & 140 & $56 \cdot 3$ & 75 & $46 \cdot 4$ & 65 & \\
\hline \multicolumn{7}{|l|}{ Maternal and birth-related characteristics } \\
\hline Mother's height $(\mathrm{cm})$, mean and SD & 163 & $162 \cdot 4$ & $5 \cdot 4$ & 163.9 & 6.5 & 0.097 \\
\hline Mother's child-care knowledge score, mean and SD & 187 & 7.4 & 1.8 & $7 \cdot 4$ & 1.6 & 0.796 \\
\hline \multicolumn{7}{|l|}{ Delivery term, $\%$ and $n$} \\
\hline Term & 173 & $50 \cdot 9$ & 88 & $49 \cdot 1$ & 85 & 0.036 \\
\hline Preterm & 12 & $83 \cdot 3$ & 10 & $16 \cdot 7$ & 2 & \\
\hline \multicolumn{7}{|l|}{ Delivery mode, $\%$ and $n$} \\
\hline Vaginal & 142 & $49 \cdot 3$ & 70 & $50 \cdot 7$ & 72 & 0.037 \\
\hline \multirow{2}{*}{\multicolumn{7}{|c|}{ Mother's anaemia during pregnancy, $\%$ and $n$}} \\
\hline & & & & & & \\
\hline Yes & 42 & $64 \cdot 3$ & 27 & 35.7 & 15 & 0.118 \\
\hline No & 143 & $50 \cdot 3$ & 72 & $49 \cdot 7$ & 71 & \\
\hline \multicolumn{7}{|l|}{ Rhesus conflict between mother and child, $\%$ and $n$} \\
\hline Yes & 31 & $67 \cdot 7$ & 21 & $32 \cdot 3$ & 10 & 0.113 \\
\hline No & 147 & $51 \cdot 0$ & 75 & $49 \cdot 0$ & 72 & \\
\hline \multicolumn{7}{|l|}{ Child's nutrition patterns } \\
\hline Duration of exclusive breast-feeding (months), mean and SD & 186 & $2 \cdot 8$ & $2 \cdot 3$ & 3.5 & $3 \cdot 1$ & 0.170 \\
\hline Duration of any breast-feeding (months), mean and SD & 153 & $7 \cdot 6$ & $6 \cdot 2$ & $12 \cdot 7$ & $10 \cdot 3$ & 0.002 \\
\hline Age of starting drinking juice (months), mean and SD & 175 & 5.9 & $2 \cdot 1$ & $7 \cdot 1$ & 3.9 & 0.040 \\
\hline Age of starting drinking cow's milk (months), mean and SD & 125 & $7 \cdot 0$ & $5 \cdot 0$ & $10 \cdot 0$ & $7 \cdot 7$ & 0.025 \\
\hline Number of child's meals in the last $24 \mathrm{~h}$, mean and SD & 188 & 3.9 & 1.5 & 3.4 & 1.2 & 0.015 \\
\hline Child's food diversity score, mean and SD & 186 & $6 \cdot 7$ & $2 \cdot 7$ & $8 \cdot 3$ & $2 \cdot 1$ & $<0.001$ \\
\hline \multicolumn{7}{|l|}{ Was breast-fed within first hour after birth, $\%$ and $n$} \\
\hline Yes & 123 & $48 \cdot 8$ & 60 & $51 \cdot 2$ & 63 & 0.063 \\
\hline No & 64 & $64 \cdot 1$ & 41 & 35.9 & 23 & \\
\hline \multicolumn{7}{|l|}{ Received cow's milk in the last $24 \mathrm{~h}, \%$ and $n$} \\
\hline Yes & 41 & $90 \cdot 2$ & 37 & $9 \cdot 8$ & 4 & 0.034 \\
\hline No & 49 & $71 . \overline{4}$ & 35 & $28 \cdot 6$ & 14 & \\
\hline \multicolumn{7}{|l|}{ Received meat in the last $24 \mathrm{~h}, \%$ and $n$} \\
\hline Yes & 100 & 44.0 & 44 & $56 \cdot 0$ & 56 & 0.005 \\
\hline No & 88 & 64.8 & 57 & $35 \cdot 2$ & 31 & \\
\hline \multicolumn{7}{|l|}{ Living standards and environment } \\
\hline Socio-economic status coefficient, mean and SD & 188 & -0.06 & 1.02 & 0.07 & 0.97 & 0.398 \\
\hline Number of times child's hands washed per day, mean and SD & 185 & 4.8 & $2 \cdot 3$ & 5.5 & $2 \cdot 4$ & 0.092 \\
\hline Using soap for hand-washing $\ddagger$, $\%$ and $n$ & & & & & & \\
\hline Rarely/never & 37 & $67 \cdot 6$ & 25 & $32 \cdot 4$ & 12 & 0.065 \\
\hline Sometimes/usually & 149 & 49.7 & 74 & $50 \cdot 3$ & 75 & \\
\hline Household heating fuel, $\%$ and $n$ & & & & & & \\
\hline Dried dung cakes & 107 & $60 \cdot 7$ & 65 & $39 \cdot 3$ & 42 & 0.026 \\
\hline Other fuel & 80 & $43 \cdot 8$ & 35 & $56 \cdot 3$ & 45 & \\
\hline Set of WV interventionsł, $\%$ and $n$ & & & & & & \\
\hline Complete set & 109 & 39.4 & 43 & $60 \cdot 6$ & 66 & $<0.001$ \\
\hline Incomplete set & 79 & 73.4 & 58 & $26 \cdot 6$ & 21 & \\
\hline
\end{tabular}

$N$, number of valid cases; $\mathrm{Hb}$, altitude-adjusted $\mathrm{Hb}$ level; WV, World Vision.

*The groups were not significantly different in variables of child's recent blood loss, mother's age at delivery, education, employment, inter-birth interval, child's birth order, age of starting drinking tea and number of family members.

†Student's $t$ test or the Mann-Whitney $U$ test for means and the $X^{2}$ test for proportions (two-sided $P$ values).

$\ddagger$ The variable was dichotomized.

significant variables, each one month increase in child's age was associated with a lower chance $(\mathrm{OR}=0.89$; $95 \% \mathrm{CI}$ $0.86,0.92)$ for the child to be anaemic. Boys were more likely $(\mathrm{OR}=3 \cdot 34 ; 95 \% \mathrm{CI} 1.36,8 \cdot 17)$ to develop anaemia than girls. Each additional centimetre of child's birth length was associated with a decreased chance $(\mathrm{OR}=0 \cdot 80 ; 95 \% \mathrm{CI}$ 0.67, 0.95) for him/her to develop anaemia. Mother's anaemia during pregnancy was associated with increased 
Table 3 Logistic regression model of determinants of anaemia among children aged 0-59 months in Talin region, Aragatsotn Province, Armenia (valid $N$ 183)

\begin{tabular}{lclr}
\hline Characteristic & OR & \multicolumn{1}{c}{$95 \% \mathrm{Cl}$} & $P$ value \\
\hline Child's age (months) & 0.89 & $0.86,0.92$ & $<0.001$ \\
Mother's anaemia during pregnancy & 4.81 & $1.51,15.39$ & 0.008 \\
Child's male gender & 3.34 & $1.36,8.17$ & 0.008 \\
Child's birth length (cm) & 0.80 & $0.67,0.95$ & 0.010 \\
Using dung cakes for heating & 3.00 & $1.25,6.96$ & 0.013 \\
Number of child's meals per day & 0.68 & $0.48,0.96$ & 0.030 \\
Complete set of WV interventions & 0.28 & $0.11,0.70$ & 0.006 \\
$\quad$ carried out & & \\
Model's fit statistics & Hosmer-Lemeshow \\
& goodness-of-fit test, \\
& $P=0.857$ \\
& Area under the ROC \\
& curve $=0.905$ \\
& Pseudo $R^{2}=0.439$ \\
\hline
\end{tabular}

WV, World Vision; ROC, receiver-operating characteristic.

*The variable was dichotomized at a threshold level reflecting the pattern of its association with the outcome on the logistic scale.

likelihood (OR $=4.81 ; 95 \%$ CI $1.51,15.39)$ for the child to develop anaemia. Feeding a child one additional time per day was associated with a lower chance $(\mathrm{OR}=0.68$; $95 \%$ CI $0.48,0.96)$ of anaemia. Using dung cakes for heating was associated with a greater chance $(\mathrm{OR}=3.00$; $95 \%$ CI $1 \cdot 25,6 \cdot 96$ ) for a child to develop anaemia. Residing in a community where the complete set of WV interventions was carried out was associated with a lower likelihood $(\mathrm{OR}=0.28 ; 95 \% \mathrm{CI} 0.11,0.70)$ for a child to be anaemic. The model reached very good fit statistics (Table 3 ).

The final linear regression model with the outcome of blood $\mathrm{Hb}$ level identified a slightly different set of independent predictors of childhood anaemia: child's gender and birth length lost their significance, while usage of any meat in the child's diet in the last $24 \mathrm{~h}$ became a marginally significant predictor of child's anaemia status with a high coefficient (4-1). The remaining determinants of childhood anaemia (child's age, number of meals per day, maternal anaemia during pregnancy, using dung cakes for heating and whether the complete set of WV interventions was carried out in the community) remained significant in the final linear regression model (Table 4). The model explained over $43 \%$ of the variability of the outcome. No interactions and no issues with collinearity were identified between the variables included in the final models (all variance inflation factor values were below 1.3).

\section{Discussion}

The present study identified altitude-adjusted mean $\mathrm{Hb}$ level of $114.3 \mathrm{~g} / \mathrm{l}$ among children aged 0-59 months residing in Talin region, Aragatsotn Province, Armenia. This level is well below the mean for under- 5 s from highincome countries $(123 \mathrm{~g} / \mathrm{l})$, is similar to that for children from Central Asia, the Middle East and North Africa
Table 4 Linear regression model for altitude-adjusted $\mathrm{Hb}$ level among children aged 0-59 months in Talin region, Aragatsotn Province, Armenia (valid N 184, $R^{2}=0.431$ )

\begin{tabular}{|c|c|c|c|c|}
\hline Characteristic & Coefficient & $95 \% \mathrm{Cl}$ & $P$ value & Partial $r$ \\
\hline $\begin{array}{l}\text { Child's age } \\
\quad(0-59 \text { months })\end{array}$ & 0.650 & $0.510,0.789$ & $<0.001$ & 0.569 \\
\hline $\begin{array}{l}\text { Mother's } \\
\text { anaemia } \\
\text { during } \\
\text { pregnancy }\end{array}$ & $-5 \cdot 111$ & $-9.996,-0.225$ & 0.040 & -0.153 \\
\hline $\begin{array}{l}\text { Using dung } \\
\text { cakes for } \\
\text { heating }\end{array}$ & $-6 \cdot 401$ & $-10 \cdot 556,-2 \cdot 246$ & 0.003 & -0.223 \\
\hline $\begin{array}{l}\text { Number of child's } \\
\text { meals per day } \\
(1-10)\end{array}$ & 1.669 & $0.062,3.276$ & 0.042 & 0.152 \\
\hline $\begin{array}{l}\text { Complete set of } \\
\text { WV } \\
\text { interventions } \\
\text { carried out }^{*}\end{array}$ & $5 \cdot 139$ & $0.667,9.610$ & 0.025 & 0.168 \\
\hline $\begin{array}{l}\text { Meat in diet in the } \\
\text { last } 24 \mathrm{~h}\end{array}$ & $4 \cdot 134$ & $-0.006,8.275$ & 0.050 & 0.147 \\
\hline
\end{tabular}

WV, World Vision; $r$, correlation coefficient.

*The variable was dichotomized.

$(114 \mathrm{~g} / \mathrm{l})$ and is slightly above the overall mean for children worldwide $(111 \mathrm{~g} / \mathrm{l})^{(2)}$. According to the most recent available data from ADHS 2005 on the prevalence of anaemia in Aragatsotn Province, the proportion of 6-59-month-old children with anaemia was $26.5 \%$ (with $16.3 \%$ mild, $3.1 \%$ moderate and $7.1 \%$ severe cases) ${ }^{(19)}$. For the same age group (6-59 months old), the prevalence of anaemia identified in the current study was $31.2 \%$ (with $16.7 \%$ mild, $13.6 \%$ moderate and $0.9 \%$ severe cases), which is not statistically significantly different from the ADHS 2005 rate, indicating that the prevalence of anaemia among children under 5 years old has been relatively stable in this region since 2005.

In the current study, the highest prevalence of anaemia was observed among children under 18 months old with a peak among those aged 6-12 months, which is consistent with reports indicating higher vulnerability to anaemia of children in the age group under 24 months with the highest prevalence during late infancy ${ }^{(6,8,15,16)}$. The most common explanation for this phenomenon is that infants' Fe stores are getting depleted at this period because of rapid growth, as growth velocity correlates significantly with the extent of Fe deficiency ${ }^{(28,29)}$. Meanwhile, dietary intake of Fe during the first 2 years of life is usually lower than recommended, especially in low-/middle-income countries $^{(8,12)}$. It is noteworthy that the observed rate of anaemia among 6-12-month-old children in Talin region (67.9\%) is comparable to the rates of anaemia among 6-9-month-old children in the most disadvantaged areas of the globe, e.g. sub-Saharan Africa (64-93\%) and Southeast Asia $(70-85 \%)^{(33)}$.

The present study identified also an alarmingly high prevalence of anaemia among the youngest age group of children in Talin region. Over half of the children aged 
0-6 months had blood $\mathrm{Hb}$ level below $110 \mathrm{~g} / \mathrm{l}$. This is worrying, as under optimal conditions with maternal Fe status, gestational age, birth size, umbilical cord clamping time and breast-feeding, the Fe stores should be adequate for at least the first $6-8$ months of life ${ }^{(33)}$. Unless caused by reasons other than Fe deficiency, the high prevalence of anaemia in the youngest age group of children indicates the possible shortcomings with perinatal care and infant feeding practices in this region. In particular, lack of Fe supplementation prenatally, immediate umbilical cord clamping and early introduction of cow's milk into the child's diet could be the main risky behaviours associated with the high prevalence of anaemia among children under 6 months old ${ }^{(33-35)}$.

The current study identified the following independent predictors of anaemia among under $-5 \mathrm{~s}$ in Talin region: child's age, gender, maternal anaemia during pregnancy, child's birth length, number of child's meals per day, presence of meat in the child's diet, using dung cakes for heating and whether the whole set of WV interventions was carried out in the community. Some of these factors, like younger age and male gender, are well-established nonmodifiable predictors of childhood anaemia ${ }^{(6,8,12-15,17,25,29)}$. While the reasons for higher vulnerability of younger children to Fe-deficient anaemia are well known, the reason for boys to be more susceptible to Fe deficiency compared with girls is a matter of debate. Various mechanisms are suggested to explain this difference, including metabolic differences in $\mathrm{Fe}$ absorption and losses, differences in proportions of lean and fat tissues in the body, and hormonal differences ${ }^{(33)}$.

Maternal anaemia during pregnancy was a strong predictor of childhood anaemia in the present study, which is consistent with other reports ${ }^{(16,26,33)}$. Although the active transfer of Fe to the fetus is maximized in Fe-deficient pregnant women as a compensatory mechanism to protect the fetus, and the findings on the immediate effect of maternal Fe deficiency on the newborn's Fe status are conflicting $^{(26,36,37)}$, longitudinal studies have demonstrated that maternal anaemia can have a long-term effect on the child's Fe stores resulting in their earlier depletion ${ }^{(26,33)}$. Lower concentration of $\mathrm{Fe}$ in the breast milk of severely Fe-deficient women could be another mechanism contributing to this depletion ${ }^{(36,37)}$.

Birth length was a protective factor for child's anaemia in the current study that mediated the influence of birth weight on anaemia status. Other studies report an independent positive relationship between child's birth weight and ferritin concentration ${ }^{(25,29)}$. A double-blinded clinical trial of Fe supplementation during pregnancy identified higher mean birth length of neonates of Fe-supplemented mothers, providing evidence for a positive relationship between birth length and maternal Fe status ${ }^{(35)}$. In the current study, birth length remained a significant predictor of child's anaemia even after controlling for maternal anaemia during pregnancy. However, the information on the latter could be under-reported because of recall bias or mother's ignorance of her anaemia status during pregnancy, especially if she had mild anaemia or did not test prenatally.

Child's meal frequency per day and inclusion of meat into the child's diet in the last $24 \mathrm{~h}$ were also independently related to child's anaemia status. More frequent meals per day and meat consumption both reduced the chance of anaemia in a child. The frequency of having meals at home was a predictor of anaemia among 2-5-year-old children in a large-scale study conducted in poor areas of China ${ }^{(38)}$. Low consumption of meat is considered to be the major cause of Fe-deficiency anaemia, especially among the poor $^{(4)}$. A number of studies have found a positive association between meat intake and child's Fe status ${ }^{(27,28,39)}$. Meat is not only a source of highly bioavailable haem Fe itself, but also acts as an enhancer of absorption of both haem and non-haem Fe from other sources, drastically increasing the overall bioavailability of dietary $\mathrm{Fe}^{(40)}$. Thus, inadequate consumption of meat during the period of introduction of solid foods and thereafter because of poverty or local diet specifics poses a child to a real danger of developing anaemia.

Using biomass fuel (dung cakes) for heating was another independent predictor of childhood anaemia in the present study. This is an interesting finding in light of a large-scale study conducted among 0-35-month-old children in India, which found a strong dose-response relationship between the use of inefficient biomass fuel (including dung cakes) for heating and cooking and the risk of anaemia in children $^{(41)}$. Another recent large-scale study also identified an independent association between anaemia among under$5 \mathrm{~s}$ and the use of unclean fuel in the household ${ }^{(42)}$. According to the WHO, dried dung and crop waste are at the bottom of the 'energy ladder' in terms of being the cheapest but the most inefficient and polluting domestic fuel $^{(43)}$. Meanwhile, indoor air pollution from the use of unclean fuel was found to disproportionately affect women and young children, as women spend many hours at the cooking devices, often keeping their young children indoors with them ${ }^{(44)}$. Similar to other studies ${ }^{(41,42)}$, the standard of living/wealth index was not independently related to child's anaemia status in the current study, suggesting that the mechanism underlying the relationship between childhood anaemia and the use of unclean domestic fuel is not explained by poverty alone.

Living in a community where the complete set of WV interventions was implemented also significantly reduced the likelihood for a child to be anaemic. This finding could indicate the effectiveness of the complete $v$. incomplete set of WV interventions in these communities. Nevertheless, these communities could be different from each other as the communities that received the complete set of WV interventions were mainly larger communities or those with easier access to the roads to the capital city, while those that received an incomplete set of 
interventions were smaller and more remote. Hence, this variable could also reflect differences between the communities other than the set of WV interventions.

The main strength of the present study was the accurate measurement of the outcome variable (i.e. blood $\mathrm{Hb}$ level) using one of the most advanced/recommended equipments (i.e. the HemoCue 201+ analyser), which resulted in realistic prevalence estimates of anaemia among under- $5 \mathrm{~s}$ in Talin region and minimized the possibility of misclassification bias during the case-control study. The main limitation of the study was its coverage of communities located in one region, Talin, which limited the generalizability of the study findings to other regions of Armenia. Other limitations included the lack of direct tests to measure the Fe status of children, the relatively small sample size of the case-control study and the self-reported nature of the majority of independent variables included in the case-control study, especially those related to child's diet, making them subject to reporting and recall biases. As the study design did not allow selecting incident cases of anaemia, we selected prevalent cases, which in theory could make it impossible to identify temporal relationships between the outcome and associated factors. However, the nature of most risk factors found in the study (e.g. mother's pregnancy anaemia, child's age, gender, birth length, biomass fuel use, etc.) excludes the possibility of a reverse temporal relationship between them and child's anaemia status. Also, the present study was the first attempt to explore determinants of anaemia among children from rural Armenia and resulted in a number of important findings that could be used by policy makers in designing interventions to reduce childhood anaemia in the country.

The identified high prevalence of anaemia among infants, with an onset in early infancy and a peak at 6-12 months of age, is disturbing given the possibly irreversible consequences of early-onset anaemia on children's development and long-term physical and cognitive performance ${ }^{(3-5)}$. This reality calls for immediate action with carefully designed and well-targeted interventions. To prevent early-onset Fe deficiency in infants, researchers are uniform in recommending to scale up strategies with known effectiveness: Fe supplementation during pregnancy, delayed cord clamping, immediate initiation and exclusive breast-feeding for 6 months, and timely and appropriate complementary feeding after 6 months ${ }^{(33,45)}$. It is very important that children receive an adequate amount of bioavailable Fe starting from the first days of the initiation of complementary feeding. This requirement could be met by adding meat to a child's daily diet. Hallberg et al. found a drastic increase in both nonhaem and haem Fe absorption from a gruel (to a level of the daily Fe requirement of a 12-month-old infant) after adding a powdered meat to it ${ }^{(40)}$.

An alternative way of providing additional $\mathrm{Fe}$ to $\mathrm{Fe}$ deplete individuals is to use Fe supplements in a form of pills or syrups ${ }^{(46)}$. This strategy requires identification of the Fe status of the recipient first, as Fe supplementation, while beneficial for Fe-deficient children, may cause harm to Fereplete children by interfering with their optimal growth, causing oxidative damage to the tissues and increasing their susceptibility to infections, particularly malaria, tuberculosis and intestinal infections ${ }^{(10,47,48)}$. Thus, this strategy should selectively target Fe-deficient children ${ }^{(45,47,48)}$. Staple food fortification with Fe is another way to reduce Fe deficiency, but the main requirement for this strategy is that the fortified food should be consumed in sufficiently large amounts by the vulnerable population groups ${ }^{(46)}$. Therefore, to prevent Fe deficiency in early childhood, Fe is usually added to commercial food items for children. However, these foods could be inaccessible and/or unaffordable for poor rural families. Alternatively, a promising approach could be to use micronutrient powders for homemade complementary food fortification, found to be successful in a number of studies ${ }^{(49,50)}$, but the success of this approach depends heavily on mothers' compliance.

Given the restrictions of Fe supplementation strategies, adequate diet and healthy environment remain the cornerstones of preventing Fe deficiency in children ${ }^{(46,51)}$. Early introduction of cow's milk into a child's diet, especially as a substitute for breast milk, a practice rather widespread in rural Armenia, should be avoided for its proven inhibitory influence on Fe absorption from other foods and for its ability to cause small intestinal haemorrhages because of inducing allergic inflammation of the intestinal mucosa ${ }^{(34)}$. There are a number of important interventions that could be undertaken in rural Armenia to eliminate the modifiable risk factors of childhood anaemia, including prevention and treatment of anaemia during pregnancy, adequate complementary feeding of children with inclusion of meat into a child's daily diet, and reduction of women's and children's exposure to inefficient biomass fuel smoke. As most of the risk factors of childhood anaemia identified in the current study are frequently reported to be determinants of anaemia in other countries as well ${ }^{(16,26,27,38,39)}$, the present study's findings could be applicable to other countries, especially those with similar economic background. In this respect, the finding on the independent relationship between using biomass fuel and childhood anaemia is of particular interest, as a considerable proportion of households not only in rural Armenia but also in rural areas in other low-/ middle-income countries use this type of fuel for heating and cooking, and yet only a few studies ${ }^{(41,42)}$ highlight the association between this behaviour and child's anaemia status. Further research specifically targeting 0-6-monthold infants is recommended to identify the predictors of early-onset anaemia in rural Armenia.

\section{Acknowledgements}

Acknowledgements: The authors are grateful to Dr Zaruhi Bakalyan for her input during the preliminary literature 
review for this paper and WV Armenia staff members Drs Naira Gharakhanyan, Ruzanna Manukyan and Arax Hovhannesyan for their contribution to the initial discussions of the project. The authors also thank Dr Tsovinar Harutyunyan at the American University of Armenia for her contribution to the project. The authors express their gratitude to the Ministry of Health of Armenia and the field workers and participants of the study. Financial support: World Vision Middle East and Eastern Europe Regional Office funded this study. Conflict of interest: V.S. is employed in the aforementioned agency. The remaining authors declare no conflict of interest. Authorship: All authors participated in conceptualizing and designing the study. A.D. acquired the data, performed the analysis and drafted the manuscript. V.P. and K.H. critically revised the manuscript for important intellectual content. All authors have read and approved the final manuscript. Ethics of buman subject participation: The study was conducted according to the guidelines laid down in the Declaration of Helsinki. The Institutional Review Board of the American University of Armenia approved the study protocol. Mothers/legal guardians of children provided written consent to participate.

\section{Supplementary material}

To view supplementary material for this article, please visit http://dx.doi.org/10.1017/S1368980015002451

\section{References}

1. Kassebaum NJ, Jasrasaria R, Naghavi M et al. (2014) A systematic analysis of global anemia burden from 1990 to 2010. Blood 123, 615-624.

2. Stevens GA, Finucane MM, De-Regil LM et al. (2013) Global, regional, and national trends in haemoglobin concentration and prevalence of total and severe anaemia in children and pregnant and non-pregnant women for 1995-2011: a systematic analysis of population-representative data. Lancet Glob Health 1, e16-e25.

3. Black RE, Victora CG, Walker SP et al. (2013) Maternal and child undernutrition and overweight in low-income and middle-income countries. Lancet 382, 427-451.

4. Black RE, Allen LH, Bhutta ZA et al. (2008) Maternal and child undernutrition: global and regional exposures and health consequences. Lancet 371, 243-260.

5. Beard JL (2001) Iron biology in immune function, muscle metabolism and neuronal functioning. J Nutr 131, 2S-2, 568S-580S.

6. Rocha DS, Capanema FD, Netto MP et al. (2012) Prevalence and risk factors of anemia in children attending daycare centers in Belo Horizonte - MG. Rev Bras Epidemiol 15, 675-684.

7. Kumar T, Taneja S, Yajnik CS et al. (2014) Prevalence and predictors of anemia in a population of North Indian children. Nutrition 30, 531-537.

8. Villalpando S, Shamah-Levy T, Ramirez-Silva CI et al. (2003) Prevalence of anemia in children 1 to 12 years of age. Results from a nationwide probabilistic survey in Mexico. Salud Publica Mex 45, Suppl. 4, S490-S498.
9. Keusch GT (2003) The history of nutrition: malnutrition, infection and immunity. J Nutr 133, issue 1, 336S-340S.

10. Collins HL (2003) The role of iron in infections with intracellular bacteria. Immunol Lett 85, 193-195.

11. Oppenheimer SJ (2001) Iron and its relation to immunity and infectious disease. J Nutr 131, 2S-2, 616S-635S.

12. Pasricha SR, Black J, Muthayya S et al. (2010) Determinants of anemia among young children in rural India. Pediatrics 126, e140-e149.

13. Tengco LW, Rayco-Solon P, Solon JA et al. (2008) Determinants of anemia among preschool children in the Philippines. J Am Coll Nutr 27, 229-243.

14. VanBuskirk KM, Ofosu A, Kennedy A et al. (2014) Pediatric anemia in rural Ghana: a cross-sectional study of prevalence and risk factors. J Trop Pediatr 60, 308-317.

15. Cardoso MA, Scopel KK, Muniz PT et al. (2012) Underlying factors associated with anemia in Amazonian children: a population-based, cross-sectional study. PLoS One 7, e36341.

16. Meyerovitch J, Sherf M, Antebi F et al. (2006) The incidence of anemia in an Israeli population: a population analysis for anemia in 34,512 Israeli infants aged 9 to 18 months. Pediatrics 118, e1055-e1060.

17. Heidkamp RA, Ngnie-Teta I, Ayoya MA et al. (2013) Predictors of anemia among Haitian children aged 6 to 59 months and women of childbearing age and their implications for programming. Food Nutr Bull 34, 462-479.

18. Tchounwou PB, Yedjou CG, Patlolla AK et al. (2012) Heavy metal toxicity and the environment. EXS 101, 133-164.

19. National Statistical Service, Ministry of Health \& ORC Macro (2006) Armenia Demographic and Health Survey 2005. Calverton, MD: National Statistical Service, Ministry of Health and ORC Macro.

20. National Statistical Service, Ministry of Health \& ORC Macro (2001) Armenia Demographic and Health Survey 2000. Calverton, MD: National Statistical Service, Ministry of Health and ORC Macro.

21. World Health Organization (2011) Haemoglobin Concentrations for the Diagnosis of Anaemia and Assessment of Severity. Vitamin and Mineral Nutrition Information System (WHO/NMH/NHD/MNM/11.1). Geneva: WHO.

22. National Statistical Service of the Republic of Armenia (2011) The results of census of Republic of Armenia of 2011. http://armstat.am/am/?nid=504 (accessed June 2015).

23. Bäck S-E, Magnusson CGM, Norlund LK et al. (2004) Multiple-site analytic evaluation of a new portable analyzer, HemoCue Hb 201+, for point-of-care testing. Point of Care 3, 60-65.

24. Domellof M, Dewey KG, Lonnerdal B et al. (2002) The diagnostic criteria for iron deficiency in infants should be reevaluated. J Nutr 132, 3680-3686.

25. Emond AM, Hawkins N, Pennock C et al. (1996) Haemoglobin and ferritin concentrations in infants at 8 months of age. Arch Dis Child 74, 36-39.

26. Kilbride J, Baker TG, Parapia LA et al. (1999) Anaemia during pregnancy as a risk factor for iron-deficiency anaemia in infancy: a case-control study in Jordan. Int J Epidemiol 28, 461-468.

27. Michaelsen KF, Milman N \& Samuelson G (1995) A longitudinal study of iron status in healthy Danish infants: effects of early iron status, growth velocity and dietary factors. Acta Paediatr 84, 1035-1044.

28. Thorsdottir I, Gunnarsson BS, Atladottir H et al. (2003) Iron status at 12 months of age - effects of body size, growth and diet in a population with high birth weight. Eur J Clin Nutr 57, 505-513.

29. Sherriff A, Emond A, Hawkins N et al. (1999) Haemoglobin and ferritin concentrations in children aged 12 and 
18 months. ALSPAC Children in Focus Study Team. Arch Dis Child 80, 153-157.

30. Sanou D \& Ngnie-Teta I (2012) Risk factors for anemia in preschool children in sub-Saharan Africa. In Anemia, pp. 171-190 [D Silverberg, editor]. Rijeka: InTech.

31. National Statistical Service, Ministry of Health \& ICF International (2012) Armenia Demographic and Health Survey 2010. Calverton, MD: National Statistical Service, Ministry of Health and ICF International.

32. Hosmer DW \& Lemeshow S (2000) Applied Logistic Regression, 2nd ed. New York: Wiley-Interscience.

33. Chaparro CM (2008) Setting the stage for child health and development: prevention of iron deficiency in early infancy. J Nutr 138, 2529-2533.

34. Oliveira MA \& Osorio MM (2005) Cow's milk consumption and iron deficiency anemia in children. J Pediatr (Rio J) $\mathbf{8 1}$, 361-367.

35. Preziosi P, Prual A, Galan P et al. (1997) Effect of iron supplementation on the iron status of pregnant women: consequences for newborns. Am J Clin Nutr 66, 1178-1182.

36. Kumar A, Rai AK, Basu S et al. (2008) Cord blood and breast milk iron status in maternal anemia. Pediatrics 121, e673-e677.

37. El-Farrash RA, Ismail EA \& Nada AS (2012) Cord blood iron profile and breast milk micronutrients in maternal iron deficiency anemia. Pediatr Blood Cancer 58, 233-238.

38. Li M, Yu D, Liu A et al. (2011) Prevalence of anemia and feeding behavior among 2-5 year-old children in poor areas of China. Wei Sheng Yan Jiu 40, 147-149 ((in Chinese).

39. Engelmann MD, Sandstrom B \& Michaelsen KF (1998) Meat intake and iron status in late infancy: an intervention study. J Pediatr Gastroenterol Nutr 26, 26-33.

40. Hallberg L, Hoppe M, Andersson M et al. (2003) The role of meat to improve the critical iron balance during weaning. Pediatrics 111, 864-870.

41. Mishra V \& Retherford RD (2007) Does biofuel smoke contribute to anaemia and stunting in early childhood? Int J Epidemiol 36, 117-129.
42. Baranwal A, Baranwal A \& Roy N (2014) Association of household environment and prevalence of anemia among children under-5 in India. Front Public Health 2, 196 .

43. World Health Organization (2006) Fuel for Life: Household Energy and Health. Geneva: WHO.

44. Fullerton DG, Bruce N \& Gordon SB (2008) Indoor air pollution from biomass fuel smoke is a major health concern in the developing world. Trans R Soc Trop Med Hyg 102, 843-851.

45. Stoltzfus RJ (2008) Research needed to strengthen science and programs for the control of iron deficiency and its consequences in young children. $J$ Nutr 138, 2542-2546.

46. World Health Organization \& Food and Agricultural Organization of the United Nations (2006) Guidelines on Food Fortification with Micronutrients. Geneva: WHO and FAO.

47. Lannotti LL, Tielsch JM, Black MM et al. (2006) Iron supplementation in early childhood: health benefits and risks. Am J Clin Nutr 84, 1261-1276.

48. Domellof M (2007) Iron requirements, absorption and metabolism in infancy and childhood. Curr Opin Clin Nutr Metab Care 10, 329-335.

49. Lundeen E, Schueth T, Toktobaev N et al. (2010) Daily use of Sprinkles micronutrient powder for 2 months reduces anemia among children 6 to 36 months of age in the Kyrgyz Republic: a cluster-randomized trial. Food Nutr Bull 31, 446-460.

50. Troesch B, van Stuijvenberg ME, Smuts CM et al. (2011) A micronutrient powder with low doses of highly absorbable iron and zinc reduces iron and zinc deficiency and improves weight-for-age Z-scores in South African children. $J$ Nutr 141, 237-242.

51. Hurrell R, Ranum P, de Pee S et al. (2010) Revised recommendations for iron fortification of wheat flour and an evaluation of the expected impact of current national wheat flour fortification programs. Food Nutr Bull 31, 1 Suppl., S7-S21. 